\title{
PRESIDENCIALISMO E QUALIDADE DA DEMOCRACIA NA AMÉRICA LATINA
}

\author{
Ana Tereza Duarte Lima de Barros ${ }^{1}$
}

\section{Resumo:}

As Constituições latino-americanas, embora inspiradas na norte-americana, dotaram os presidentes de fortes poderes legislativos. Dessa maneira, o déficit democrático na América Latina não decorre puramente do presidencialismo, mas do tipo de presidencialis mo adotado, que promove presidentes hiper fortes com permissão constitucional para atuarem ativamente na arena legislativa. No primeiro capítulo trazemos os argumentos dos principais teóricos a respeito do presidencialismo na América Latina. No terceiro e quatro capítulos abordamos a importância do desenho constitucional para a qualidade da democracia. Por fim, concluímos que as amplas faculdades legislativas dos presidentes latino-americanos estariam associadas ao déficit democrático existente na região.

Palavras-chave: Presidencialismo; Democracia; América Latina

\section{PRESIDENTIALISM AND THE QUALITY OF DEMOCRACY IN LATIN AMERICA}

\begin{abstract}
:
Latin American constitutions, although inspired by the North-American one, have endowed the presidents of strong legislative powers. Thus, the democratic deficit in Latin America does not stem purely from presidentialism, but the type of presidentialism adopted, which promotes strong presidents constitutionally allowed to work in the legislative arena. In the first chapter, we bring the main arguments about presidentialism. In the third and fourth chapters, we address the importance of the constitutional design for the quality of democracy. Finally, we conclude that the broad legislative powers of Latin American presidents are associated with the existing democratic deficit in the region.
\end{abstract}

Keywords: Presidentialism; Democracy; Latin America

\section{INTRODUÇÃO}

Vários foram os teóricos que defenderam ser o presidencialismo a razão da instabilidade democrática dos países latino-americanos. Ocorre que, as Constituições vigentes no continente, embora tenham copiado o modelo norte-americano, dotaram os presidentes de vastos poderes legislativos, poderes estes que os homônimos norte-americanos não possuem, a exemplo dos poderes de veto parcial e de iniciativa legislativa exclusiva. Logo, o déficit democrático na América Latina não decorre puramente do presidencialismo, mas do tipo de

\footnotetext{
${ }^{1}$ Professora do Centro Universitário Maurício de Nassau (UNINASSAU-PE) e do Centro Universitário Brasileiro (UNIBRA-PE). Mestre em Ciência Política pela Universidade Federal de Pernambuco (UFPE). Bacharela em Direito pela Universidade Católica de Pernambuco (UNICAP).
} 
presidencialismo adotado pelos países da região, que promove presidentes hiper fortes, que possuem permissão constitucional para atuarem na arena legislativa, muitas vezes em questões que caberiam ao legislativo decidir.

No primeiro capítulo fazemos um levantamento dos principais teóricos que abordaram a questão do presidencialismo na América Latina. No segundo capítulo trazemos a problematização feita por Shugart e Carey (1992), que demonstram empiricamente o quão forte são os presidentes latino-americanos. No terceiro capítulo buscamos demonstrar a importância do desenho constitucional, mais especificamente como a Constituição lida com a separação dos poderes. No quarto capítulo trazemos algumas considerações acerca da qualidade da democracia na América Latina. Por fim, concluímos que as amplas faculdades legislativas dos presidentes latino-americanos estariam associadas ao déficit democrático existente na região.

\section{O presidencialismo como razão da instabilidade democrática dos países latino- americanos}

Juan Linz (1997, p. 31-32) chama atenção para o fato de que a maioria das democracias estáveis, notadamente as europeias, possuem regimes parlamentaristas, enquanto que maioria das democracias instáveis possuem regimes presidencialistas. As constituições vigentes nos países presidencialistas dotariam seus executivos de consideráveis poderes, porém, o principal problema desse tipo de sistema político residiria, primeiramente, na legitimidade democrática dual, ou seja, o fato de que tanto o presidente como o legislativo foram eleitos diretamente pelo povo, de modo que ambos gozam da mesma legitimidade democrática; e em segundo lugar, na rigidez que esse tipo de sistema possui, visto que o congresso e o executivo são elegidos para períodos fixos e gozam de independência, ou seja, nem o congresso pode destituir o presidente, nem o presidente pode dissolver o congresso.

No caso da legitimidade democrática dual, Linz (1997, p. 34/38-39) chama atenção para uma possível paralisia que poderia ocorrer caso o presidente e a maioria legislativa sejam de partidos distintos. Nesse caso, não há mecanismos para resolver o problema, visto que ambos poderes gozam da mesma legitimidade. Por outro lado, ao se eleger para período fixo, o presidente não poderá ser destituído em situações extremas, como nos casos em que perdeu 
a confiança do seu partido. Já nos sistemas parlamentaristas, em caso de graves crises institucionais, sempre há a possibilidade de se convocar novas eleições.

Por fim, dentre as críticas feitas por Linz ao presidencialismo, destaco a questão do “vencedor leva tudo". Para o autor, em uma eleição presidencial, como o vencedor ganha todo o executivo, não precisaria compartilhar o poder (LINZ, 1997, p. 46).

Arend Lijphart (1997, p. 148/150/157) concorda com Linz quanto aos problemas da legitimidade democrática dual e da rigidez fixa, e acrescenta mais uma crítica: o presidencialismo tende à democracia majoritária. Para Lijphart, esse tipo de sistema político torna difícil uma democracia consensual. Como o presidente é um executivo de uma só pessoa, esse tipo de sistema iria de encontro aos compromissos e pactos necessários à boa governabilidade democrática, o que é muito mais fácil de se conseguir em sistemas parlamentaristas, onde o executivo é um órgão colegiado.

Outra crítica feita por Lijphart (1997, p. 160) e que é de fundamental importância para o presente trabalho, é no que diz respeito ao poder de veto sobre a legislação que os presidentes possuem. Com a exceção dos casos em que a maioria legislativa seja da oposição, o poder de veto seria um poder presidencial fortíssimo, que transformaria o presidente em uma verdadeira "terceira câmara na legislatura".

Giovanni Sartori (1997, p. 173) traz ao debate a questão da ineficácia dos sistemas presidências, uma vez que, para serem eficazes, três requisitos necessitariam serem preenchidos: flexibilidade ideológica, partidos débeis e sem disciplina, e uma política focada no âmbito local. Caso esses três requisitos sejam preenchidos é que o presidente poderia ganhar os votos necessários no Congresso, pois os parlamentares ficariam interessados em receber, em troca, favores para os seus distritos.

Stepan e Skach (1997, p. 205), seguindo a linha de Linz, defendem que a independência de mandatos do presidente e da legislatura, assim como o fato de que os presidentes muito raramente conseguem maioria legislativa, obriga-os a governarem poder decreto. Dessa forma, o presidencialismo tenderia a produzir situações de estagnação e quebra democrática.

Ao criar o conceito de “democracia delegativa", Guillermo O’Donnell (1994, p. 8/12) traz ao debate um novo tipo de democracia típico dos países presidencialistas. 
Democracias delegativas seriam justamente aquelas não institucionalizadas, ou seja, não consolidadas, como seria o caso das democracias latino-americanas. O líder delegativo seria aquele que se crê a "encarnação do país". Assim, como os eleitores depositaram sua confiança nele, acredita estar legitimado a decidir, como bem entender, os rumos do país. As outras instituições, como o Judiciário e o Legislativo, são vistas como um obstáculo a ser superado. Dito tipo de líder delegativo apenas encontra espaço para emergir em sistemas presidencialistas.

\section{O problema são os poderes legislativos do presidente}

Terry M. Moe (2013, p. 15) critica os estudiosos do presidencialismo por terem dedicado muito de seus estudos apenas ao aspecto pessoal da presidência. Ocorre que a presidência também é uma instituição, logo, é preciso focar no aspecto institucional, excluindo fatores pessoais. É o que faremos nesta dissertação.

Mainwaring e Shugart possuem mais de um trabalho dedicado a refutar alguns dos argumentos dados por Linz. Primeiramente, os autores expõem a debilidade da assertiva de que o presidencialismo leva à instabilidade democrática. Seria complexo chegar a essa conclusão, visto que o presidencialismo existe sobretudo na América Latina, o que torna difícil saber se o problema é devido ao sistema em si ou a fatores socioeconômicos. Por outro lado, o tipo parlamentarista existe predominantemente na Europa, onde as instituições já estão há tempo consolidadas (MAINWARING; SHUGART, 1997, p. 12).

Também não seria verdadeira a alegação de Linz de que no presidencialismo o vencedor leva tudo. Os autores demonstram que, sistemas parlamentaristas com partidos disciplinados e um partido majoritário, como é o caso do sistema de Westminster, oferecem menos controles. Já o sistema de pesos e contrapesos, característico do presidencialismo, "inibe tendências do tipo "o vencedor leva tudo"”. Ainda acrescentam que no tipo presidencialista é mais provável que o gabinete seja dividido entre vários partidos (MAINWARING; SHUGART, 1993, p. 199- 200).

Seria igualmente importante levar em consideração as diferenças entre os tipos de presidencialismo, visto que alguns desses tipos são mais favoráveis a uma democracia estável do que outros. O poder dos presidentes derivaria dos poderes constitucionais e dos poderes 
partidários. Algumas constituições preveem vastos poderes, enquanto outras concedem poderes limitados (MAINWARING; SHUGART, 1997, p. 13).

Mainwaring e Shugart (1997, p. 203-204) defendem que os riscos do presidencialismo podem ser atenuados se o presidente gozar de poderes legislativos fracos.

Nos Estados Unidos os presidentes possuem consideráveis poderes, contudo, como bem explica Humberto Nogueira Alcalá (1985, p. 92)

Na América Latina o Presidente da República é um órgão colegislador, a diferença do Presidente dos Estados Unidos. Os presidentes latinoamericanos dispõem, com frequência, das seguintes atribuições que não possui constitucionalmente o Presidente dos Estados Unidos: inciativa de lei; iniciativa exclusiva de lei em certas matérias; competência para convocar a legislatura extraordinariamente; declaração de urgência na tramitação de projetos de lei; participação no debate parlamentar da lei, através dos Ministros de Estado; veto parcial; e delegação de faculdades legislativas ao Presidente da República. (...) O veto suspensivo parcial é a atribuição de caráter legislativo mais importante com que contam os presidentes na América Latina. Este tipo de veto parcial ou "item veto" permite ao Presidente da República eliminar ou melhorar certos aspectos dos projetos de lei sem maior compromisso respeito ao rechaço total do projeto, que pode ter disposições essenciais para o desenvolvimento do programa presidencial. Ele outorga uma maior liberdade de ação aos chefes de Estado latino-americanos do que a que dispõe o Presidente da República dos Estados Unidos, que só pode exercer um veto total do projeto. Dita situação permite ao Congresso introduzir matéria de seu interesse nos projetos que o Presidente está obrigado a aprovar, pela sua importância para o desenvolvimento da política presidencial (ALCALÁ, 1985, p. 92).

$\mathrm{Na}$ América Latina as constituições seguiram tendência contrária aos Estados Unidos e dotaram seus presidentes de vastos poderes legislativos.

Cumpre esclarecer que não pretendemos elogiar o sistema norte-americano ou tachar o presidente estadunidense de fraco. Entendemos que não existem presidentes fracos, apenas uns são mais fortes que outros. Estudos já comprovaram que os sucessivos presidentes dos Estados Unidos obtiveram alto grau de sucesso ao tentarem implementar suas agendas. Dentre as razões do sucesso encontra-se sua capacidade de barganha e de apelo ao público, assim como seu poder de controle sobre a burocracia e os recursos públicos (MORGENSTERN et al, 2013, p. 38/41-42). Assim, os presidentes norte-americanos conseguem implementar suas agendas se utilizando de táticas informais, enquanto os presidentes latino-americanos encontram seus poderes de influenciar a agenda institucionalizados, traduzidos nos vastos poderes legislativos previstos nos textos constitucionais.

Segundo Mainwaring e Shuagart 
Quando o presidente tem grandes poderes legislativos, restringe-se muito a capacidade do congresso para debater, fazer composição para aprovar projetos e negociar acordos em questões controvertidas que a sociedade enfrenta. Ao contrário, o presidente assume enorme importância legislativa e tem armas formidáveis para ajustar a legislação a seus caprichos e limitar a construção do consenso na assembleia (MAINWARING; SHUGART, 1993, p. 206).

Os autores compararam os poderes legislativos dos presidentes utilizando seis variáveis: veto total, veto parcial, decreto, iniciativa legislativa exclusiva, iniciativa orçamentária e proposta de referendo. Cada variável foi valorada de 0 a 4 , em que 0 seria considerado um poder muito fraco, e 4 um poder muito forte. Os autores chegaram à conclusão de que o fracasso das democracias latino-americanas não é acidente, visto que os presidentes desses países obtiverem altos escores em matéria de poderes legislativos (MAINWARING; SHUGART, 1993, p. 205- 206).

Shugart e Carey (1992) também trataram da questão dos poderes presidenciais. Assim como no trabalho de Mainwaring e Shugart (1993), Shugart e Carey (1992) trataram dos poderes legislativos do presidente, que seriam o de veto total, veto parcial, decreto, iniciativa legislativa exclusiva, iniciativa orçamentária e proposta de referendo. Da mesma forma que os autores citados anteriormente, esses autores também valoraram cada variável de 0 a 4.

Para Shugart e Carey (1992, p. 148), os sistemas que obtiverem altos escores em matéria de poderes legislativos presidenciais são os mesmos que apresentam problemas de estabilidade democrática. Da mesma forma, sistemas que dotam os presidentes de poder sobre a composição do gabinete e fracos poderes no que diz respeito à separação e sobrevivência do Congresso e do Executivo também possuem democracias problemáticas.

\section{Desenho constitucional e Poder Executivo}

A origem dos regimes latino-americanos é o presidencialismo norte-americano, que criou o conceito de separação de poderes, baseado no sistema de freios e contrapesos. Dito sistema surgiu para evitar que o parlamento usurpasse do poder. Para James Madison, era necessário separar e dotar de independência funcional cada um dos poderes, submetendo-os ao controle dos eleitores. Os poderes então responderiam a interesses distintos, de modo que o presidente responderia aos interesses nacionais, os senadores ao eleitorado de seus respectivos 
Estados, e os deputados aos eleitores de seu distrito. Igualmente, para evitar a usurpação, seria necessário que cada um dos poderes possuísse poder de veto, ou seja, um mecanismo de controle sobre os demais poderes. Assim, o sistema de freios e contrapesos, característico do presidencialismo, exige que cada poder possua um poder de veto relativamente simétrico em matéria de legislação (NEGRETTO, 2003, p. 43-45).

Esse sistema de freios e contrapesos possui debilidades, como por exemplo, o fato de que permite a atores minoritários manter o status quo através do veto, assim como os distintos interesses de cada poder podem levar a um bloqueio da atividade legislativa. Para driblar essas debilidades, foi instituído na América Latina um novo modelo de freios e contrapesos, dando ao presidente amplos poderes sobre a legislação, mesmo que conte com pouco apoio parlamentar (NEGRETTO, 2003, p. 49-50/55-56).

De 1978 a 2008 todos os países da América Latina reformaram suas Constituições, tendo 15 países promulgado novas Cartas. Essas reformas, além de terem expandido substancialmente os direitos individuais e coletivos, também tenderam a incrementar os poderes legislativos dos presidentes. Gabriel Negretto destaca três fatores que explicam as mudanças constitucionais: mudança de regime político, crise política e mudanças nas preferências de alocação de poder (2009, p. 38-39).

Entre 1978 e 2008, das 140 emendas, 34 trataram de questões relativas a separação dos poderes entre executivo e legislativo. Enquanto os poderes de governo do presidente foram restringidos, os poderes legislativos foram aumentados. Os poderes presidenciais foram limitados, por exemplo, no que diz respeito à nomeação de autoridades locais e juízes. Inclusive, várias constituições removeram a possibilidade de o presidente nomear prefeitos. Contudo, o poder de agenda setting dos presidentes foi substancialmente incrementado. As áreas em que seu poder mais foi acentuado foram: iniciativa exclusiva de lei sobre questões econômicas e financeiras importantes; definição do orçamento; medidas de urgência que devem ser votados pelo congresso em um prazo pré-estabelecido; decretos com força de lei; referendo. No início do século XX, nenhum presidente latino-americano possuía ditos poderes, já no início do século XXI, praticamente todos possuem (NEGRETTO, 2013, p. 23/36-38). 
E o que fez com que o congresso aprovasse emendas dotando o presidente de maiores poderes legislativos? Conforme Shugart e Carey (1992, p. 186-187), que possuem uma visão cooperativa, os deputados querem prolongar sua carreira como políticos, dessa forma, lhes parece conveniente criar uma figura central, qual seja o presidente, para cuidar da política nacional e ser responsivo perante os cidadãos. Igualmente, essa alocação de poderes no presidente tornaria mais eficiente a provisão de políticas públicas. Já para os que possuem uma visão distributiva, os constituintes legislam pensando nas vantagens que poderão obter na competição política (NEGRETTO, 2013, p. 50). Para Maxwell A. Cameron (2013, p. 37), espera-se do executivo que ele sempre saiba agir em momentos de indecisão e mesmo quando o marco legal não é muito certo, logo, necessita de poderes.

Cheibub et al (2011, p. 22-23) apresentam duas proposições de por que a concentração de poderes ocorreu. Um dos argumentos (e que coincide com o de Cameron) é o de que, como o Executivo chefia a administração pública, para ser proativo, necessita ter poderes para solucionar situações complexas. Além do mais, a concentração de poderes no presidente facilita a accountability. O outro argumento é que a concentração reflete a usurpação de poderes pelo Executivo, ou seja, facilita o surgimento de caudilhos que tomam o poder do Congresso e passam a legislar em seu lugar, através de medidas de urgência e decretos. Acreditamos que o que ocorre na América Latina é um misto dos dois argumentos.

Para John Carey (2009, p. 173), presidentes fortes geram benefícios "quando o poder presidencial pode ser configurado de modo a incentivar a deliberação no prazo pela legislatura e a negociação entre os ramos de governo, e não como um substituto para ou impedimento para a elaboração de políticas legislativa”.

Com respeito à indagação de por que os constitucionalistas optaram por constituições que concentram o poder, Roberto Gargarella (2014, p. 285-290) oferece três hipóteses: primeiramente, porque os constituintes talvez não achassem que essa concentração fosse gerar tensões, dada a separação de poderes; outra hipótese é a de que a expansão de direitos simultaneamente ao fortalecimento do presidente geraria uma espécie de compensação, ou seja, geraria equilíbrio constitucional; por fim, encontra-se a visão de autores como Viciano Pastor e Martínez Dalmau, para quem esse tipo de concentração não é só apropriada, mas necessária para a efetivação dos direitos incorporados. 
Gargarella critica duramente essas visões, especialmente a última, e concordamos com o autor. A concentração de poderes presidenciais, usada como justificativa para a efetivação de direitos, faz com que surjam "presidências imperiais" (ACKERMAN, 2010). O problema dessa visão, como bem destaca Gargarella, reside no fato de que se sobrestima o poder de controle dos cidadãos e se subestima o poder de ação do Executivo. O que ocorre é justamente o contrário, os cidadãos passam a ter mais dificuldades para controlar o Executivo, além do mais, o controle através do voto é bastante limitado e é exercido apenas uma vez. Da mesma forma, a capacidade de os presidentes atuarem de forma discricionária é notável, basta olhar para os obstáculos que impõem ao congresso, para as intervenções federais e para os decretos de necessidade e urgência (GARGARELLA, 2014, p. 293-296).

Figueiredo e Limongi (1997, p. 4) demonstram que, no Brasil, entre 1989 e 1994, o presidente dominou a iniciativa legislativa, como ocorria durante o período da ditadura militar. As iniciativas do Executivo somaram $85 \%$ do total de iniciativas, estando pouca coisa distante dos $90 \%$ do regime ditatorial.

Luís Gustavo Mello Grohmann (2001, p. 88/91-94) observou se os arranjos teóricos da separação de poderes encontravam-se presentes institucionalmente em todos os países latinoamericanos, com a exceção de Cuba. Suas principais conclusões foram de que na maioria dos países a separação de poderes não é tão forte, sendo Bolívia (que mudou de Constituição após o estudo), Brasil e Chile as exceções. No que diz respeito à independência e checagem dos poderes, na maioria dos países a independência seria fraca e as checagens médias. Brasil, Chile e Colômbia seriam os países que teriam o maior percentual (maior que 70\%) de independência do Executivo, seguidos de Argentina, Paraguai, Peru e Uruguai. Já o poder de checagem legislativa é mais forte no Uruguai e no Peru, passando dos $60 \%$. Na Venezuela, Brasil, Argentina e Uruguai é onde a independência legislativa é maior, e no México, Costa Rica e El Salvador onde é menor.

SANTOS et al (2014, p. 513/516-517) fazendo uma análise qualitativa (QCA) em que comparam 30 presidentes latino-americanos durante o período de 1993 a 2010, chegaram à conclusão de que "um desenho institucional favorável ao Executivo e uma divisão do Congresso em blocos ideológicos bem diferenciados favorece o controle presidencial da agenda legislativa". Ou seja, os autores concluíram que o executivo tem maior influência sobre a agenda quando o desenho institucional lhes favorece. Da mesma forma, teria o 
legislativo maior poder sobre a agenda se as regras institucionais lhe favorecessem. Contudo, salientam que essa vantagem institucional do presidente tem pouca relevância quando este possui maioria parlamentar. Igualmente, seus poderes institucionais têm menor impacto quando o Congresso é altamente fragmentado.

\title{
4. Qualidade da democracia na América Latina
}

As democracias latino-americanas estão longe de serem consideradas democracias consolidadas. A falta de justiça social e o déficit político-institucional ainda assolam a região. É no intuito de melhorar esse déficit institucional e, consequentemente, a governabilidade democrática, que são levadas a cabo as inúmeras reformas constitucionais (HENRÍQUEZ; ZOVATTO, 2009, p. 48-49).

O fato de as instituições latino-americanas não serem consolidadas faz com que, muitas vezes, as atribuições constitucionais estejam muito distantes da realidade política. Por exemplo, onde as instituições são consolidadas, ainda que um presidente tenha fortes poderes para emitir decretos com força de lei, tenderá a exercer esse direito de forma limitada. Já onde as instituições não se encontram consolidadas, o presidente abusa dos decretos. Segundo Nohlen, não existe nenhuma atribuição de competências "ideal” para o Executivo, visto que tudo irá depender de fatores como a cultura política, a percepção que os outros atores têm do Executivo, a tradição institucional e as circunstâncias políticas (2009, p. 34-35).

Nas palavras de Persson e Tabellini (2004, p. 96)

\begin{abstract}
O efeito negativo do presidencialismo só está presente entre as democracias com pontuações mais baixas para a qualidade da democracia; isso sugere que talvez não seja o governo presidencial em si que é prejudicial para o desempenho económico, mas sim a combinação de um executivo forte e diretamente eleito em um ambiente institucional fraco onde o abuso de poder político não pode ser facilmente prevenido (PERSSON; TABELLINI, 2004, p. 96).
\end{abstract}

Segundo dados do IDB (2006), expostos por Marcus André Melo (2009), nenhuma das legislaturas latino-americanas atua de forma proativa (o caso norte-americano, em que o parlamento introduz a legislação por iniciativa própria). Melo salienta a importância de, além de observamos os poderes dos presidentes, prestarmos atenção também no poder de contrapeso do Congresso. Ou seja, para que um regime democrático possa sobreviver, seria necessário um sistema de pesos e contrapesos robusto e que prevaleça a lei e a ordem (o que 
envolve pluralismo midiático, autonomia do judiciário e accountability horizontal). A concentração de poderes explicaria a falta de autonomia das instituições. Logo, "a competição política e a alternância de poder em um contexto em que a mídia é livre e independente levaria ao surgimento de instituições autônomas que são necessárias para fazer contrapeso ao Executivo". O declínio da competição política somado a um aumento da concentração de poderes levaria a um declínio da independência das instituições (MELO, 2009, p. 32/44/49$50)$.

Não existe uniformidade na concentração desse poder entre as Constituições latinoamericanas, de forma que cada texto constitucional o faz de maneira diferente. Os textos de Venezuela e Bolívia, por exemplo, não conferem poderes de veto, nem total, nem parcial, a seus presidentes, porém, lhes garantem poderes muito fortes para emitir decretos e convocar referendos. Por outro lado, a Constituição brasileira dá, embora não muito fortes, poderes de veto ao seu presidente, assim como também lhe confere poderes relativamente fortes para emitir decretos, porém, não dá poderes para que o Presidente da República possa convocar a cidadania para referendos.

Fazendo-se um balanço geral, as Constituições de Venezuela, Bolívia e Brasil concentram fortes poderes em torno da figura presidencial. No entanto, enquanto questiona-se se Venezuela e Bolívia são, de fato, poliarquias, não há dúvidas de que o Brasil é uma democracia. Surge, então, a pergunta: em que medida o desenho constitucional, que permite essa concentração de poderes nas mãos do presidente, afeta a qualidade da democracia nos países da região?

É sabido que países da região, como a Venezuela, a Bolívia e o Equador, têm seu status de democracia posto em questão, sendo considerados pela literatura como formas diminuídas da democracia. Há quem considere o regime existente nesses países como "híbrido" (DIAMOND, 2002; MORLINO, 2004; DIAMOND; MORLINO, 2005), como “semidemocrático" (MAINWARING; BRINCKS; PÉREZ-LIÑÁN, 2001; MAINWARING; PÉREZ-LIÑÁN, 2008), como “democracias delegativas” (O’DONNELL, 1994), como “autoritarismos competitivos" (LEVITSKY Y WAY, 2002), como "democracias iliberais" (ZAKARIA, 1998), e como "regimes eleitorais autoritários" (SCHEDLER, 2002). 
Tanto a Venezuela, como a Bolívia, quanto o Equador possuem presidentes que se utilizam de um estilo de liderança considerado populista, que se caracteriza "pela relação direta e paternalista entre líder-seguidor, sem mediações organizativas ou institucionais" (FREIDENBERG, 2011, p. 9). Pouco tempo após terem chegado ao poder, Hugo Chávez, Evo Morales e Rafael Correa convocaram Assembleias Constituintes para criarem novas Constituições, seguindo a linha doutrinária constitucional que Roberto Viciano Pastor e Rubén Martínez Dalmau (2011) chamaram "novo constitucionalismo latino-americano".

Essas novas Constituições aumentaram substancialmente o poder dos presidentes, sobretudo o seu poder de emitir decretos e convocar referendos. Assim, parece ter razão Sebastian Edwards (2009, p. 233) quando diz que essa possibilidade de o presidente poder recorrer a instrumentos da democracia direta, como plebiscitos e referendos, para poder avançar em sua agenda, eleva a nível constitucional uma das principais características do populismo, que é o apelo direto às massas.

\section{Considerações Finais}

O presente trabalhou buscou, primeiramente, apresentar a principal literatura referente ao presidencialismo e mostrar o quão defendido foi a ideia de que a razão da instabilidade democrática na América Latina era o tipo de sistema de governo. Em segundo lugar, o trabalho buscou mostrar que mais que o presidencialismo, o fator chave para entender as democracias latino-americanas reside nos fortes poderes legislativos que os presidentes latino-americanos possuem. Por fim, concluímos que as Constituições da América Latina, ao dotarem seus presidentes de fortes poderes legislativos, podem ser associadas ao déficit democrático existente na região.

\section{Referências}

ACKERMAN, Bruce. The Decline and Fall of the American Republic. Cambridge: Harvard University Press, 2010.

ALCALÁ, Humberto Nogueira. El presidencialismo en la práctica política. Nueva Sociedad, n. 77 , p. 88-98, 1985. 
CAMERON, Maxwell A. Strong Constitutions: Social-Cognitive Origins of the Separation of Powers. Oxford: Oxford University Press, 2013.

CAREY, John M. What Sort of Strong President? In: ELLIS, Andrew; HENRÍQUEZ, J. Jesús OROZCO; ZOVATTO; Daniel. Cómo hacer que funcione el sistema presidencial. México: UNAM, 2009. pp. 173-189.

CHEIBUB, José Antonio; ELKINS, Zachary; GINSBURG, Tom. Latin American Presidentialism in Comparative and Historical Perspective. Texas Law Review, v. 89, p. 1-33, 2011.

DIAMOND, Larry. Thinking About Hybrid Regimes. Journal of Democracy, v. 13, n. 2, p. 21-35, 2002.

DIAMOND, Larry; MORLINO, Leonardo. Assessing the Quality of Democracy. Baltimore: John Hopkins University Press, 2005.

EDWARDS, Sebastián. Populismo o mercados: el dilema de América Latina. Bogotá: Norma, 2009.

FIGUEIREDO, Argelina Cheibub; LIMONGI, Fernando. Presidential Power and Party Behavior in the Legislature, 1997, Guadalajara. Anais.

FREIDENBERG, Flavia. Los nuevos liderazgos populistas y la democracia en América Latina. Lasa Forum, v. 42, n. 03, p. 9-11, 2011.

GARGARELLA, Roberto. La sala de máquinas de la Constitución: dos siglos de constitucionalismo en América Latina (1810-2010). Buenos Aires: Katz, 2014.

GROHMANN, Luís Gustavo Mello. A separação de poderes em países presidencialistas: a América Latina em perspectiva comparada. Revista de Sociologia e Política, n. 17, p. 75-106, 2001.

HENRÍQUEZ, J. Jesús Orozco; ZOVATTO, Daniel. Alcance de los poderes presidenciales en los países latino-americanos. In: ELLIS, Andrew; HENRÍQUEZ, J. Jesús OROZCO; ZOVATTO; Daniel. Cómo hacer que funcione el sistema presidencial. México: UNAM, 2009. pp. 45-97. 
LEVITSKY, S.; WAY, L. The Rise of Competitive Autoritarism. Journal of Democracy, v. 13, n. 2, p. 51-65, 2002.

LIJPHART, Arend. Presidencialismo y democracia mayoritaria: observaciones teóricas. In: LINZ, Juan; VALENZUELA, Arturo. (Org.). Las crisis del presidencialismo: perspectivas comparadas. Madri: Alianza Universidad, 1997. v. 1.

LINZ, Juan J. Democracia presidencial o parlamentaria. Qué diferencia implica? In: LINZ, Juan; VALENZUELA, Arturo. (Org.). Las crisis del presidencialismo: perspectivas comparadas. Madri: Alianza Universidad, 1997. v. 1.

LISSIDINI, Alicia. Democracia directa en Uruguay y en Venezuela: nuevas voces, antiguos procesos. In: CAMERON; HERSHBERG; SHARPE, Nuevas instituciones de democracia participativa en América Latina. México: Flacso, 2012. p. 665-772.

MAINWARING, Scott; SHIGART, Matthew. Juan Linz, presidencialismo e democracia: uma avaliação crítica. Novos Estudos, n. 37, p. 191-213, 1993.

Presidentialism and Democracy in Latin America: Rethinking the Terms of the Debate. In: MAINWARING, Scott; SHUGART, Matthew. (Org.). Presidentialism and Democracy in Latin America. Cambridge: Cambridge University Press, 1997.

MAINWARING, Scott; BRINKS, Daniel; PÉREZ LIÑÁN, Aníbal. Classifying Political Regimes in Latin America. Studies in Comparative International Development, v. 36, n. 1, p. $37-65,2001$.

MAINWARING, Scott; PÉREZ LIÑÁN, Aníbal. Latin America Democratization since 1978. In: Hagopian, Frances y Mainwaring, The Third Wave of Democratization in Latin America. New York: Cambridge University Press, 2008. p. 14-59.

MELO, Marcus André. Strong Presidents, Robust Democracies? Separation of Powers and Rule of Law in Latin America. Brazilian Political Science Review, v. 3, n. 2, p. 30-59, 2009.

MOE, Terry M. Presidentes, instituciones y teoria. In: ALESSANDRO, Martín; GILIO, Andrés. (Org.). La dinámica del Poder Ejecutivo em América Latina: estudios comparados sobre la institución presidencial. Buenos Aires: INAP, 2013. 
MORGENSTERN, Scott; POLGA-HECIMOVICH, John; SHAIR-ROSENFIELD, Sarah. Tall, Grande, or Venti: Presidential Powers in the United States and Latin America. Journal of Politics in Latin America, v. 5, n. 2, p. 37-70, 2013.

MORLINO, L. What is a "Good” Democracy. Democratization, v. 11, n. 5, p. 10-32, 2004.

NEGRETTO, Gabriel. Diseño constitucional y separación de poderes en América Latina. Revista Mexicana de Sociología, v. 65, n. 1, p. 41-76, 2003. Making Constitutions: Presidents, Parties, and Institutional Choice in Latin America. Cambridge: Cambridge University Press, 2013.

Paradojas de la reforma constitucional en América Latina. Journal of Democracy en Español, v. 1, n. 1, p. 38-54, 2009.

NOHLEN, Dieter. El Poder Ejecutivo en el presidencialismo: alternativas en debate. In: ELLIS, Andrew; HENRÍQUEZ, J. Jesús OROZCO; ZOVATTO; Daniel. Cómo hacer que funcione el sistema presidencial. México: UNAM, 2009. pp. 33-43.

O’DONNELL, Guillermo. Democracia delegativa. Journal of Democracy, v. 5, n. 1, p. 7 23,1994 .

PERSSON, Torsten; TABELLINI, Guido. Constitutions and economic policy. Journal of Economic Perspectives, v.18, n. 1, p. 75-98, 2004.

SANTOS, Manoel Leonardo; PÉREZ-LIÑÁN, Aníbal; MONTERO, Mercedes García. El control presidencial de la agenda legislativa en América Latina. Revista de Ciencia Política, v. 34, n. 3, p. 511-536, 2014.

SARTORI, Giovanni. Ni presidencialismo ni parlamentarismo. In: LINZ, Juan; VALENZUELA, Arturo. (Org.). Las crisis del presidencialismo: perspectivas comparadas. Madri: Alianza Universidad, 1997. v. 1.

SCHEDLER, A. Elections Without Democracy: The Menu of Manipulation. Journal of Democracy, v. 13, n. 2, p. 36-50, 2002.

SHUGART, Matthew Soberg; CAREY, John M. Presidents and Assemblies: Constitutional Design and Electoral Dynamics. Cambridge: Cambridge University Press, 1992. 
STEPAN, Alfred; SKACH, Cindy. Presidencialismo y parlamentarismo en perspectiva comparada. In: LINZ, Juan; VALENZUELA, Arturo. (Org.). Las crisis del presidencialismo: perspectivas comparadas. Madri: Alianza Universidad, 1997. v. 1.

PASTOR, Roberto Viciano.; DALMAU, Rubén Martínez. Fundamentos teóricos y prácticos del nuevo constitucionalismo latinoamericano. Gaceta Constitucional, n. 48, p. 307-328, 2011.

ZAKARIA, F. El surgimiento de la democracia iliberal. BID-Gobierno del Ecuador. Publicación ocasional. Programa de Apoyo al Sistema de Gobernabilidad Democrática, 1998. 